\title{
Contraofensiva neoliberal. La Escuela Austríaca de Economía en el centro estratégico de la disputa
}

\section{Ignacio Andrés Rossi*}

Universidad Nacional de Luján /

Universidad Nacional de General Sarmiento, Argentina

ignacio.a.rossi@gmail.com

María Pula de Büren, Contraofensiva neoliberal. La Escuela Austríaca de Economía en el centro estratégico de la disputa, Buenos Aires, CLACSO, 2020, 337 pp.

De Büren presenta una perspectiva crítica en torno al conocimiento, luego de retomar las suposiciones de Karl Popper sobre la neutralidad y la relación casi amorosa con la verdad, sigue a Nietzche y Foucalt para decir sin rodeos que la ciencia, como muchas otras cosas, es ante todo una práctica social que debería ser interpelada. En este sentido, este libro se propone analizar las contribuciones discursivas de la Escuela Austríaca de Economía entre los siglos XIX y XX, corriendo el eje clásico centrado en la Escuela de Chicago, en torno a las disputas por la definición de un nuevo modelo civilizatorio: el neoliberalismo. Este libro cobra vigencia, tanto en el caso argentino como latinoamericano, donde gobiernos con importantes sesgos evidentemente neoliberales se presentaron nuevamente en la actualidad luego del fracaso de fines del siglo $X X$.

\footnotetext{
* Licenciado en Historia (UNLu), Magister en Historia Contemporánea (UNGS) y doctorando en Historia (UNSAM), Argentina.

\section{(c) (i) (8)} No-Comercial 4.0 Internacional.
}

Secuencia. E-ISSN 2395-8464 http://secuencia.mora.edu.mx/

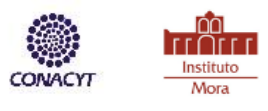


En un primer capítulo se trata la emergencia de la Escuela Austriaca de Economía y sus condiciones históricas de surgimiento. Se retoma al exponente Carl Menger en Viena a finales de la década de 1870 en conjunción con la relevancia geopolítica e histórica de Austria. El examen retoma los largos siglos de dominio en España, el Sacro Imperio Romano Germánico, Flandes y una poderosa e histórica dinastía vinculada al academicismo en tanto Francisco José I eligiera a Menger, designado profesor en la Universidad de Viena por decisión real, como el instructor a su sucesor en el trono del archiduque Rodolfo. Este recorrido permite a la autora reconstruir la relevancia política y territorial de Viena y la larga tradición de los Habsburgo en construir estrategias de gobierno y socialización fuera de sus fronteras en centro Europa: de aquí el planteo del neoliberalismo como un arte civilizatorio. Así, en el marco de una intensa actividad intelectual a raíz de las reformas liberales en las universidades vienesas de fines del siglo XIX y principios del XX, se examinan los pasajes de formas de gobiernos monárquicos a parlamentarios donde grupos burgueses comienzan a prepararse intelectualmente para desempeñar una dirección cultural en el resto de la población. He aquí la línea de la autora: el discurso tiene un papel principal. La Escuela Austríaca nació en disputa por la preeminencia con la Escuela Histórica Alemana, que tuvo varias generaciones entre 1840-1870, y a la cual se la puede distinguir básicamente por la crítica a la economía clásica en torno al individualismo, su boga por la intervención del Estado, una metodología específica centrada en las monografías históricas, el rechazo del método deductivo y de la existencia de leyes de carácter universal. En suma, el resto del capítulo recorre el pensamiento de otros exponentes como Friedrich von Wieser y Eugen Bohm-Baerk, seguidores y precursores de Menger, Ludwin von Mises y Friedrich von Hayek, continuadores de su obra. Pero lo original es que el análisis se centra no tanto en la veracidad de sus postulaciones sino más bien en la construcción discursiva empleada para dar batalla en el ámbito de las ideas.

Secuencia. E-ISSN 2395-8464 
Así, en un segundo capítulo De Büren se centra en la importancia del discurso mangeriano contra el marxismo, especialmente en las disputas en torno al valor. Mientras que Marx apuntó al trabajo, aunque en franca crítica a la teoría ricardiana, para precisar la apropiación del producto y elaborar su teoría de la plusvalía y la explotación, el mangerianismo aseguró que el valor de las mercancías residía en el capital. Especialmente la teoría subjetiva del valor y la revolución marginalista desde los aportes de Menger como León Walras durante la segunda mitad del siglo XIX constituyen el baluarte de los esfuerzos por dotar a la economía de soportes epistemológicos y científicos. Los precursores de la Escuela Austriaca se asumen como portadores de una teoría del valor científica, que fue centrada más en los determinantes de la demanda que de la oferta mediante el concepto de utilidad marginal derivando como consecuencia hacia una mayor importancia de la concepción individualista y atómica de la sociedad. Luego de realizar un recorrido por las teorías hegemónicas del valor contemporáneo y la defensa de pensadores como John Stuart Mill y Alfred Marshall como de la economía clásica de Smith y Ricardo, la autora se centra en la teoría del valor mengeriana en su doble aspecto: valor trabajo y valor capital. La autora destaca cómo la revolución marginalista en Austria con Menger tuvo un carácter más radical, especialmente contra el historicismo alemán (llamados “socialista de sillón”) que la inglesa con Jevons, aspecto profundizado aún más como batalla abierta contra el marxismo por parte de Bawerk. De Büren asegura que aquí existen antecedentes discursivos del neoliberalismo: desplazamiento del trabajo como elemento primordial del valor por la necesidad humana como principio motor mediante una revalorización del capital y la tierra en una época en que la estabilidad social debía lidiar entre la desintegración monárquica, el avance de las masas y/o las burguesías. De Büren detecta cómo el aporte mengeriano revaloriza la producción en su capacidad multiplicadora: la producción y su crecimiento ya no es fruto del trabajo sino del capital, de su tiempo de espera, Secuencia. E-ISSN 2395-8464 
del riesgo y la incertidumbre. También en este sentido puede decirse cómo desde la obra de Menger adquieren mayor legitimidades en el proceso productivo quienes más lejos están del producto final: quien más riesgo corre, quien ofrece la tierra, el capital y en menor medida el trabajo. La autora señala con algún acierto cómo desde el punto de vista discursivo era necesario separar, e incluso desembarazar, a la teoría del valor de la producción para centrarse en el estudio del individuo y así discutir al marxismo como consecuentemente a la economía clásica: operación discursiva que permite reivindicar terratenientes y capitalistas.

El capítulo 3 aborda la primera generación de la Escuela Austriaca, especialmente la irrupción de Ludwin Von Mises. Ya no se trataba de legitimar los privilegios burgueses y sectores capitalistas de la población ante el peligro de la clase trabajadora frente a la desvanescencia de las formas monárquicas de organización social. Por el contrario, se puede inscribir a Von Mises en un mundo social aún más agitado donde el marxismo era una posibilidad como forma de organización social (desde la Comuna de París hasta la Revolución Rusa. En este marco, como sostiene la autora, Von Mises velará por la teoría austriaca inicial, resistiendo y organizando una contraofensiva contra el avance de los trabajadores. Von Mises no solo participó como Ministro de Hacienda vienense, sino que en sus propias palabras evitó la instauración del comunismo. Von Misen no solo se dedicó a cuestionar y descalificar al marxismo sino también toda su obra al criticar todo tipo de intervención estatal en la economía. Se puede mencionar en este sentido su teoría monetaria y del ciclo económico dedicada a explicar la crisis de 1930, con gran difusión por parte de von Hayek, donde considera la expansión monetaria estatal como un mecanismo de redistribución e imposición fiscal, reivindicó el patrón oro y deslegitimizó a los Bancos Centrales frente a la desregulación e independencia del sistema bancario. En este sentido, De Büren afirma que Von Misen construyó un aparato discursivo que le permitió afirmar la imposibilidad de cualquier forma Secuencia. E-ISSN 2395-8464 
de organización social distinta de la garantizada por el capitalismo argumentada sobre bases científicas de las que carecerían los conjuntos de ideas intervencionistas y marxistas. Con respecto a las teorías del valor, aspecto al que sus antecesores le dedicaron gran esfuerzo, Von Mises dio un vuelco en tanto propuso dejar de lado la discusión en torno a la explotación para centrarse en la factibilidad real que detentaba la implementación de nuevas formas de organización social. En suma, en este apartado la autora realiza un prolífico recorrido biográfico, artístico y teórico de Von Mises que resulta de gran valor para poner en tela de juicio el aparataje conceptual y discursivo construido dese la oposición a otras artes de gobierno entre fines del siglo XIX y la primera mitad del XX.

El capítulo cuatro directamente arremete contra los aportes teóricos epistemológicos de Von Hayek al campo de la sociedad y la economía. De Büren asegura que Von Hayek continuó la línea de los padres fundadores de la Escuela Alemana, especialmente la de Von Mises, con la deslegitimación de cualquier tipo de organización social capitalista mediante el empleo de armas discursivo-epistemológicas. Así se comprenderán sus premisas centradas en remarcar la imposibilidad del cálculo económico en el socialismo y cualquier tipo de intervencionismo asociado al totalitarismo. Ideas, a su vez, conectadas con la defensa de un Estado de Derecho y la privatización de la emisión monetaria. En el contexto de posguerra la visión de Von Hayek rechazó la inevitabilidad del socialismo entendiendo que cualquier mecanismo de dirección consciente sobre el mercado conduciría a la servidumbre, postura discutida a los socialistas de la época respecto a los orígenes del nazismo. En términos de Von Hayek y su teoría epistemológica, es posible conocer la teoría general para tener un rango de posibilidades, pero nunca será posible conocer los resultados concretos. En la economía, entendía el alemán, puede tenerse un modelo que relacione las variables del mercado pero no se pueden predecir ni los precios ni las cantidades concretas: de esta forma quedan Secuencia. E-ISSN 2395-8464 
descalificadas las políticas de corte keynesianas. También así se comprende que en materia de política monetaria Von Hayek abogara porque el dinero, como una mercancía más, fuera puesto en manos de la competencia privada en detrimento del monopolio estatal, responsable único de la emisión sin respaldo, inflación y devaluación de la moneda. En suma, este apartado se torna central para comprender la hegemonía que tendrá el neoliberalismo a partir de las crisis inflacionarias de los años 1970 y, luego de un recorrido también por la criminalización de las organizaciones y protestas obreras y la idea de un Estado de Derecho para el mercado. El último capítulo cierra con un análisis en Argentina sobre las posturas de la revista Ideas Sobre la Libertad durante la segunda mitad del siglo XX: una publicación periódica del Centro de Estudios Sobre la Libertad, donde De Büren reconoce una importante filiación de la escuela austríaca de economía. La autora examina puntos clave como la lucha contra el comunismo un tanto vulgarizada al asimilarse a cualquier tipo de intervención estatal como un totalitarismo. De esta forma la autora logra desentrañar las particularidades del caso latinoamericano y, especialmente argentino, donde los neoliberales locales abogaban por la intervención armada y la persecución ideológica en aras de consolidar una sociedad de acuerdo con los valores e ideales libertarios del neoliberalismo imbricando así acción militar y protección de la libertad individual. En suma, lo que De Büren entiende como la "filosofía de la libertad”, que alcanzara amplia difusión en los años 1960 y 1970, es un conjunto de valores como la limitación del poder gubernamental, la reducción impositiva, el desarrollo de la libre competencia, la no planificación, la no vinculación con los partidos políticos, entre otros. En este sentido, resulta central la resignificación del concepto de democracia que realizan los neoliberales relacionada a un Estado de Derecho de mercado como parte de una democracia liberal que restringe los poderes del ejecutivo. Esto último en clara alusión al perjudicial peronismo, régimen que era entendido como una manifestación de atraso respecto de los Secuencia. E-ISSN 2395-8464 
países más desarrollados para evitar un devenir totalitario. Esta plataforma se torna viable para comprender las intervenciones militares en Argentina y Chile, por mencionar solo algunas, y los intentos por remover lo que se entendía como democracias populares resumidas al sufragio universal.

Creo que este libro se torna valioso en tanto corre el eje de análisis tradicional y se aventura al examen de raíces históricas más profundas para analizar el neoliberalismo: la Escuela Austríaca de Economía. Pero también, se desarrolla un análisis imbricado con las condiciones históricas concretas de quienes producían las teorías económicas: desde terratenientes a propietarios con intereses puntuales. Esto permite desentrañar una mirada no ingenua estableciendo relaciones concretas entre las intenciones de los actores y sus herramientas teórico-discursivas para lograrlo. Por último, también puede decirse que tomar como eje de entendimiento al neoliberalismo y sus primeros desarrollos teóricos en torno a sus ideas de organización social permite abandonar las miradas sesgadamente economicistas que sus precursores tuvieron para poner en tela de juicio que sociedad queremos, especialmente reflexionando a partir del pasado reciente argentino y de los actuales sistemas democráticos que aún hoy en día deben mucho en materia económica y de inclusión social a sus ciudadanos. 